\title{
Multilayer bioactive glass/zirconium titanate thin films in bone tissue engineering and regenerative dentistry
}

This article was published in the following Dove Press journal:

International Journal of Nanomedicine

24 April 2013

Number of times this article has been viewed

\author{
Masoud Mozafari 1,2 \\ Erfan Salahinejad ${ }^{1,3}$ \\ Vahid Shabafrooz' \\ Mostafa Yazdimamaghani' \\ Daryoosh Vashaee ${ }^{4}$ \\ Lobat Tayebi ${ }^{1,5}$ \\ 'Helmerich Advanced Technology \\ Research Center, School of Materials \\ Science and Engineering, Oklahoma \\ State University, Tulsa, OK, USA; \\ ${ }^{2}$ Biomaterials Group, Faculty of \\ Biomedical Engineering (Center of \\ Excellence), Amirkabir University of \\ Technology, Tehran, Iran; ${ }^{3}$ Department \\ of Materials Science and Engineering, \\ School of Engineering, Shiraz \\ University, Shiraz, Iran; ${ }^{4}$ Helmerich \\ Advanced Technology Research \\ Center, School of Electrical and \\ Computer Engineering, Oklahoma \\ State University, Tulsa, OK, USA; \\ ${ }^{5}$ School of Chemical Engineering, \\ Oklahoma State University, Tulsa, \\ OK, USA
}

\begin{abstract}
Surface modification, particularly coatings deposition, is beneficial to tissue-engineering applications. In this work, bioactive glass/zirconium titanate composite thin films were prepared by a sol-gel spin-coating method. The surface features of the coatings were studied by scanning electron microscopy, atomic force microscopy, and spectroscopic reflection analyses. The results show that uniform and sound multilayer thin films were successfully prepared through the optimization of the process variables and the application of carboxymethyl cellulose as a dispersing agent. Also, it was found that the thickness and roughness of the multilayer coatings increase nonlinearly with increasing the number of the layers. This new class of nanocomposite coatings, comprising the bioactive and inert components, is expected not only to enhance bioactivity and biocompatibility, but also to protect the surface of metallic implants against wear and corrosion.
\end{abstract}

Keywords: bioactive glass, zirconium titanate, spin-coating, microstructural properties, bone/dental applications, tissue engineering

\section{Introduction}

The use of bone and dental implants continues to grow as many people are injured during physical activities. The conventional metallic implants used in hard-tissue engineering do not bond or integrate with natural bone tissues; therefore, bioactive coatings are of interest to improve the bone-bonding performance of metallic implants. In recent years, zirconia-based bioceramics have been used in biomedical applications because of their resistance to fracture, excellent biocompatibility, low cost, and high strength. ${ }^{1}$ Zirconium titanate $\left(\mathrm{ZrTiO}_{4}\right)$, with an orthorhombic $\alpha-\mathrm{PbO}_{2}$-type structure, can also be considered a suitable ceramic material in biomedical applications. ${ }^{2-4} \mathrm{ZrTiO}_{4}$ thin films and coatings have attracted much attention recently in biomedical applications that require biocompatibility and bioactivity. ${ }^{5}$ Among different metal oxides, the combination of zirconium and titanium has recently gained much attention, due to its additional toughening mechanism related to the $\mathrm{ZrTiO}_{4}$ phase in composites. ${ }^{6}$ Zirconium oxide and titanium dioxide are promising ceramics, and composites of these two materials exhibit high surface area, high thermal stability, and strong mechanical strength. ${ }^{7,8}$

Although widespread studies have been conducted on lead zirconate titanate (PZT), titania $\left(\mathrm{TiO}_{2}\right)$, and zirconia $\left(\mathrm{ZrO}_{2}\right)$ films, little systematic work has been reported on $\mathrm{ZrTiO}_{4}$ coatings and thin films, especially those considered in biomedical fields. Recently, Bavya Devi et al ${ }^{9}$ investigated the structure and bioactivity of $\mathrm{ZrTiO}_{4}$ coatings on a stainless steel (SS) alloy by a nonhydrolytic sol-gel method. They concluded that the coatings improved the bioactivity of the substrate by facilitating the apatite formation.
Helmerich Advanced Technology

Research Center, School of Materials

Science and Engineering and School of

Chemical Engineering, Oklahoma State

University, Tulsa, OK 74106, USA

Tel + I 9185948634

Email lobat.tayebi@okstate.edu 
Alternatively, bioactive glass materials can be used to enhance bone-bonding ability. Upon implantation, bioactive glasses tend to form biologically active apatite layers which act as an interface enabling a strong bonding with bone. This class of bioactive materials was first developed by Hench and Buscemi ${ }^{10}$ for coating the femoral stem of hip prostheses for cementless fixation. Bioactive glass materials exhibit osteoconductive properties defined as the characteristic of bone growth in porosities and bonding along the surface. They are also resorbable due to their mineral composition containing calcium and phosphorus similar to natural bones. In terms of biocompatibility and bioactivity, they have definitely superior advantages compared with $\mathrm{ZrTiO}_{4}$. These important advantages come from sustained release from calcium and phosphorous right after implantation. Nevertheless, their disadvantage lies in their low mechanical strength, which limits their applications. It has been shown that nanocomposite coatings of bioactive glass and other bioceramics can take advantage of the superior characteristics of the bioactive glass part and the advantages of the other component. ${ }^{11}$ Recently, Yazdanpanah et a ${ }^{12}$ reported the replacement effects of bioactive glass by nanocrystalline forsterite bioceramics on the biomineralization, microstructural, and mechanical properties. Surprisingly, they observed that the addition of forsterite provided mechanisms to improve the toughness of the bioactive glass matrix without deteriorating its biomineralization properties. In addition, the resulting enhancement in fracture toughness indicated the potential of the prepared nanocomposites as advanced biomaterials for load-bearing bone tissue-engineering applications.

A variety of coating techniques have been used for the preparation of thin films, such as sol-gel process, solution growth technique, molecular beam epitaxy, pulse laser deposition, spin coating, DC reactive magnetron sputtering, electrophoretic deposition, electrolytic deposition, metal organic chemical vapor deposition, spray pyrolysis, etc. Among them, sol-gel spin coating has attracted more attention due to its simplicity, reproducibility, and potential. ${ }^{13}$ The spin-coating process is used for coatings with circular symmetry, and the surface is held normal to the axis of rotation of the spin coater. This technique has various processing parameters such as viscosity, surface tension, amount of the sol, speed and duration of rotation, humidity and temperature, and so on. These processing parameters affect the thickness, roughness, porosity, and refractive index of the films. Daniels et al ${ }^{14}$ fully discussed the mechanisms responsible for spin coating. In another study, Rehg and Higgins discussed the effect of the processing parameters based on numerical calculations on colloidal systems. ${ }^{15}$ These detailed studies concluded that the deposition on the substrates by spin coating is one of the simplest preparation methods of thin films. In addition, the coating layers applied by this technique are high quality due to good homogeneity and reproducibility.

In this paper, the structure of multilayer bioactive glass/ $\mathrm{ZrTiO}_{4}$ thin films obtained by a particulate sol-gel spin-coating method is characterized by transmission electron microscopy (TEM), scanning electron microscopy, atomic force microscopy, and spectroscopic reflection. Additionally, a natural polymer, carboxymethyl cellulose, was used to improve the dispersion of the synthesized nanoparticles in the aqueous sol.

\section{Methods}

\section{Preparation of bioactive glass}

Sol-gel-derived bioactive glass powders, composed of $60 \%$ $\mathrm{SiO}_{2}, 36 \% \mathrm{CaO}$, and $4 \% \mathrm{P}_{2} \mathrm{O}_{5}(\mathrm{~mol} \%)$, were prepared through hydrolysis and condensation of a mixed solution of tetraethoxysilane (TEOS; $\mathrm{Si}\left[\mathrm{OC}_{2} \mathrm{H}_{5}\right]_{4}$ ), triethylphosphate (TEP; OP $\left.\left[\mathrm{OC}_{2} \mathrm{H}_{5}\right]_{3}\right)$, and calcium nitrate tetra-hydrate $\left(\mathrm{Ca}\left[\mathrm{NO}_{3}\right]_{2} \cdot{ }_{4} \mathrm{H}_{2} \mathrm{O}\right)$, as reported by Taherkhani et al ${ }^{16}$ for a basic $58 \mathrm{~S}$ bioactive glass. An anitric acid $\left(\mathrm{HCl}: \mathrm{HNO}_{3}\right)$ solution was used as the catalyst for the hydrolysis and condensation reactions. All the reagents were purchased from Sigma-Aldrich (St Louis, MO, USA). In order to prepare the sol, deionized water and $2 \mathrm{M}$ nitric acid with a volume ratio of 6:1 were stirred. TEOS and TEP, respectively, were poured into the water/acid solution and stirred at room temperature for 1 hour each (the molar ratio of TEOS/TEP solution to water was calculated as 1:12). Then, calcium nitrate was added to the resultant solution and stirred at 323 Kelvins until all the nitrate salt was completely dissolved. The solution was cast in a cylindrical teflon container and kept sealed for 10 days at room temperature to allow the hydrolysis and a polycondensation reaction to take place to form the gel. The gel was kept in a sealed container and heated at $343 \mathrm{~K}$ for an additional period of 3 days. A small hole was inserted in the lid to allow the leakage of gases while heating the gel to $393 \mathrm{~K}$ for 2 days to remove all the water. Subsequently, the dried gel after crushing was further calcined at $973 \mathrm{~K}$ for 1 day (for nitrate removal), followed by ball milling (SVD15IG5-1; LG Company, Yeouido-dong, Seoul, South Korea) at $400 \mathrm{rpm}$ for 10 hours to obtain $58 \mathrm{~S}$ bioactive glass powders.

\section{Preparation of $\mathrm{ZrTiO}_{4}$}

A $\mathrm{ZrTiO}_{4}$ sol was prepared, according to the methods of Salahinejad et al. ${ }^{17}$ Initially, $9.1 \mathrm{mmol}$ of zirconium tetrachloride $\left(\mathrm{ZrCl}_{4} 99.5 \%\right.$; Alfa Aesar, Ward Hill, MA, 
USA) and $9.1 \mathrm{mmol}$ of titanium tetrachloride ( $\mathrm{TiCl}_{4} 99.99 \%$; Alfa Aesar) were added to $200 \mathrm{~mL}$ of deionized water and stirred for 2 hours. Afterwards, the $\mathrm{pH}$ value of the solution was enhanced to 7 by using a $2 \mathrm{M} \mathrm{NaOH}$ solution. The hydrogel was rinsed several times with deionized water to remove chloride ion and centrifuged at $6000 \mathrm{rpm}$ for 10 minutes. To prepare a sol with appropriate viscosity for spin coating, $75 \mathrm{~mL}$ of deionized water and $2 \mathrm{wt} \%$ carboxymethyl cellulose ([CMC] sodium salt; Alfa Aesar) were added, followed by sonication for 1 hour. The resultant sol viscosity was $80 \mathrm{mPaS}$, measured using a Bohlin C-VOR rheometer (Malvern Instruments Ltd, Worcestershire, UK).

\section{Preparation of bioactive glass $/ \mathrm{ZrTiO}_{4}{ }^{-}$ coated implants}

Austenitic stainless steel substrates were ground gradually by No 180-3000 emery papers (Shor International Corporation and The I. Shor Company, Madison, NJ, USA), mirror-polished with 1 and $0.1 \mu \mathrm{m}$ alumina powders (Thermo Fisher Scientific Inc., Waltham, MA, USA), and then ultrasonically cleaned in acetone, ethanol, and distilled water. A sol containing $50 \mathrm{wt} \%$ of the milled bioactive glass and $50 \mathrm{wt} \% \mathrm{ZrTiO}_{4}$ was then spin coated on the substrate at $3000 \mathrm{rpm}$ for 60 seconds. The wet coated samples were immediately dried at $353 \mathrm{~K}$ for 1 hour in an oven. Further heat treatment was conducted under a nitrogen atmosphere at a constant rate of $276 \mathrm{~K} /$ minute by heating to $473 \mathrm{~K}$, holding for 15 minutes, heating to $673 \mathrm{~K}$, holding for 15 minutes, heating to $973 \mathrm{~K}$, and holding for 1 hour. This thermal cycle was designed based on the $\mathrm{ZrTiO}_{4}$ 's thermal behavior for gradual removal of residual volatile materials and preparing thin and uniform films, where the material presents a sharp weight loss when heating from 373 to $673 \mathrm{~K} .{ }^{17-19}$ The above processes, including deposition, drying, and sintering, were repeated three times to prepare mono-, double-, and triple-layer films.

\section{Preparation of simulated body fluid (SBF) solution}

The simulated body fluid solution was prepared by dissolving reagent-grade $\mathrm{NaCl}, \mathrm{KCl}, \mathrm{NaHCO}_{3}, \mathrm{MgCl}_{2} \cdot 6 \mathrm{H}_{2} \mathrm{O}, \mathrm{CaCl}_{2}$, and $\mathrm{KH}_{2} \mathrm{PO}_{4}$ into distilled water and buffering at $\mathrm{pH} 7.25$ with TRIS (trishydroxymethyl aminomethane) and $1 \mathrm{~N} \mathrm{HCl}$ solution at $310 \mathrm{~K}$. All reagents were purchased from SigmaAldrich. The final composition of the prepared SBF is given in Table 1 and is compared with the human blood plasma. It should be also noted here that SBF is a solution highly supersaturated with respect to apatite. ${ }^{12}$
Table I lon concentrations of simulated body fluid (SBF) and human blood plasma

\begin{tabular}{lll}
\hline Ion & Plasma (mmol/L) & SBF $(\mathbf{m m o l} / \mathbf{L})$ \\
\hline $\mathrm{Na}^{+}$ & 142.0 & 142.0 \\
$\mathrm{~K}^{+}$ & 5.0 & 5.0 \\
$\mathrm{Mg}^{+2}$ & 1.5 & 1.5 \\
$\mathrm{Ca}^{+2}$ & 2.5 & 2.5 \\
$\mathrm{Cl}^{-}$ & 103.0 & 147.8 \\
$\mathrm{HCO}_{3}^{-}$ & 27 & 4.2 \\
$\mathrm{HPO}_{4}^{-2}$ & 1.0 & 1.0 \\
$\mathrm{SO}_{4}^{-2}$ & 0.5 & 0.5 \\
\hline
\end{tabular}

\section{Sample characterization}

TEM (JEM-2100; JEOL, Tokyo, Japan) at an acceleration voltage of $200 \mathrm{kV}$ was performed to evaluate the powder particles.

The surfaces were studied by a field-emission scanning electron microscope ([SEM] Hitachi S-4800, Hitachi High Technologies America, Dallas, TX, USA) and Veeco Multimode atomic force microscope, ([AFM] Bruker AXS Inc, Madison, WI, USA) to evaluate the film quality and roughness.

The film thickness was also measured by a NanoSpec 3000 system (Nanometrics, Milpitas, CA, USA) utilizing a modern small spot spectroscopic reflectometer.

The coating adhesion to the substrates was also evaluated by the adhesive tape test (in accordance with ASTM D 3359), by adhering a piece of adhesive tape (Scotch, CAT No W-12; $3 \mathrm{M}$ Commercial Office Supply Division, USA), $12 \times 15 \mathrm{~mm}$, to the surface of the samples using gentle thumb pressure. Then, the tape was peeled at an angle of $90^{\circ}$ to the substrate.

In addition, the apatite formation capability of the samples was examined by Fourier transform infrared spectroscopy (FTIR) with Agilent Cary 680 FTIR spectrometer (Agilent Technologies, Santa Clara, CA, USA). For infrared (IR) analysis, $1 \mathrm{mg}$ of the scraped samples was carefully mixed with $300 \mathrm{mg}$ of $\mathrm{KBr}$ (infrared grade) and palletized under vacuum. Then, the pellets were analyzed in the range of $0-1000 \mathrm{~cm}^{-1}$ with $4 \mathrm{~cm}^{-1}$ resolution averaging 120 scans.

\section{Statistical analysis}

All experiments were performed in five replicates. The results are given as mean \pm standard error. The statistical analysis was performed by one-way ANOVA and Tukey's test with significance reported when $P<0.05$. Also, for the investigation of group normalizing, the Kolmogorov-Smirnov test was used. 

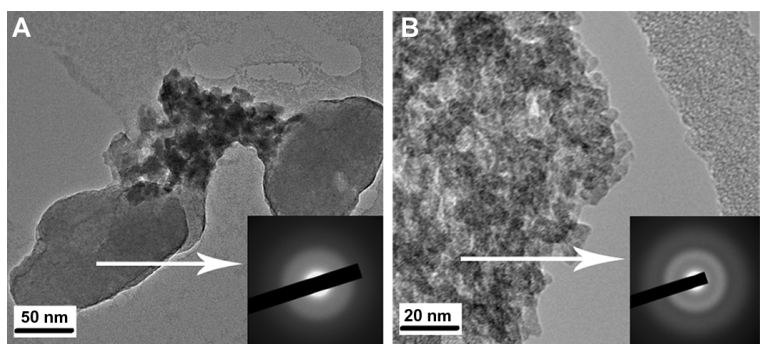

Figure I TEM micrographs and SAD patterns of the bioactive glass powder (A), and TEM micrograph and SAD pattern of the zirconium titanate powder (B). Abbreviations: SAD, selected area diffraction; TEM, transmission electron microscope.

\section{Results and discussion}

Figure $1 \mathrm{~A}$ and $\mathrm{B}$ show the TEM micrographs and selected area diffraction patterns of the synthesized powders. According to Figure 1A, the average particle size of the bioactive glass powders was around $100 \mathrm{~nm}$, and the related selected area diffraction pattern indicated homogeneous featureless diffraction halos attributed to an amorphous structure. In contrast, the amorphous $\mathrm{ZrTiO}_{4}$ particles had an average size of $5 \mathrm{~nm}$ as shown in Figure 1B. In addition, the particle size distribution for bioactive glass and $\mathrm{ZrTiO}_{4}$ was in the range of 75 to $120 \mathrm{~nm}$ and 2 to $6 \mathrm{~nm}$, respectively, as measured by importing the TEM images into Image-J technical software (Developed by Wayne Rasband, NIH, USA).

After mixing and applying the powders as the coating materials, the microstructure of the samples was examined. The uniform coverage of the coatings obtained in the first deposition step was initially limited by agglomeration of the particles as droplets on the substrate. To obtain a complete coverage, the concentration of bioactive glass/ $\mathrm{ZrTiO}_{4}$ solution was optimized by the further addition of deionized water, while the deposition conditions were the same. The solutions having viscosities less than $80 \mathrm{mPaS}$ could not cover the surface completely. In addition, to obtain crack-free thicker films, a multilayer approach, comprising three deposition steps, was employed. In fact, due to the shrinkage and higher removal rate of volatile materials during the sintering process, thicker films are more prone to cracking. Figures $2 \mathrm{~A}-\mathrm{C}$ show the SEM micrographs of the mono-, double-, and triple-layer coated surfaces, respectively. The crack-free and homogeneous bioactive glass $/ \mathrm{ZrTiO}_{4}$ composite coatings were achieved with no observable defects. It is worth mentioning that the desirable characteristics of the coatings can also be attributed to the presence of $\mathrm{CMC}$ as an effective dispersant and stabilizer. When CMC adsorbs onto the particles, it can cause a desirable steric stabilization by making a negative charge around the particles, which depresses their hydrophobicity and agglomeration. According to the steric stabilization theory for colloidal dispersions, ${ }^{20-23}$ a strong steric repulsion between the particles is an essential factor for having defect-free coatings.

To determine the thickness of the multilayer coatings, spectroscopic reflectometry was used. Figure 2D shows an
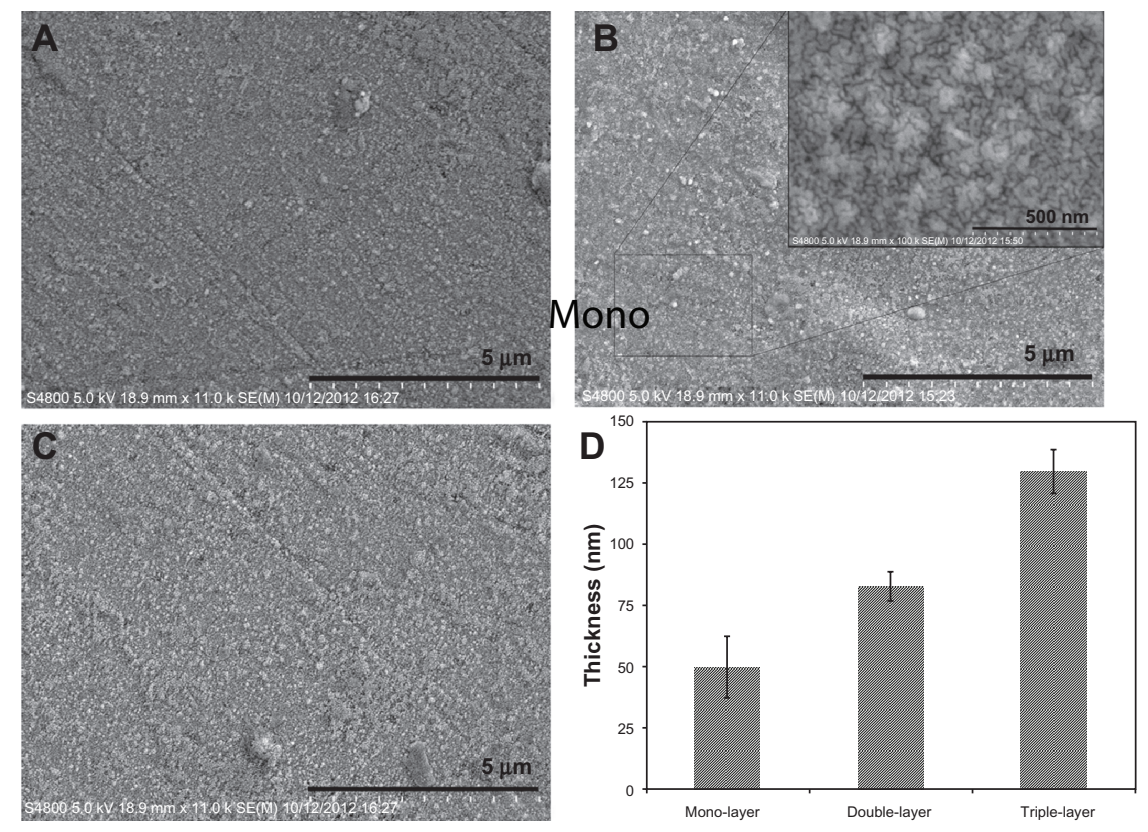

Figure 2 Scanning electron microscope (SEM) micrographs of the surface of the mono- (A), double- (B), and triple-layered (C) coated samples and thickness values of the deposited films (D).

Note: Inset is a high-magnification SEM micrograph. 


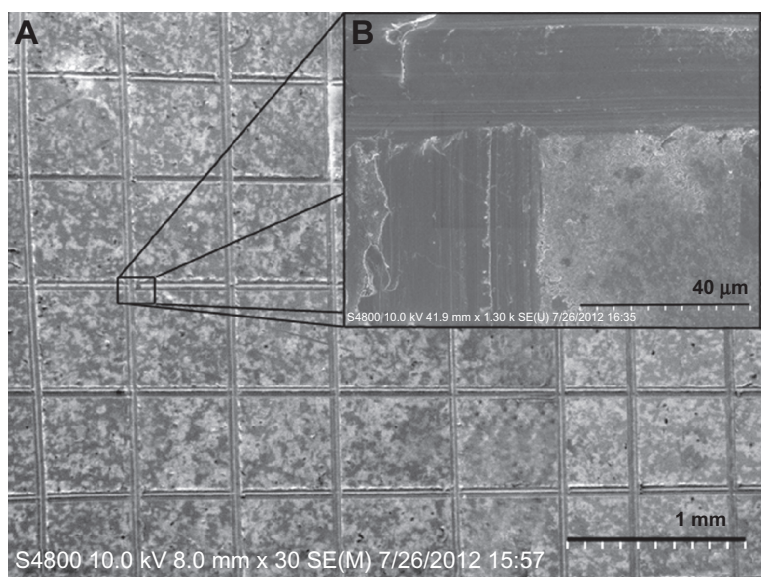

Figure 3 Typical scanning electron microscope micrographs of the surface morphologies of the triple-layered coated sample after the adhesion tape test. (A) Low magnification; (B) high magnification.

enhancement in thickness by increasing the number of the layers. As can be seen, the thickness values for the mono-, double-, and triple- coatings are around 50, 83, and $130 \mathrm{~nm}$, respectively. Also, the thicknesses of individual layers in the multilayer coatings are not the same, because some particles in the successive coated layers tend to deposit on pores and defects of the previous layer. In addition, after the evaporation of thin liquid films, layers of square or cubic packing were created by self-assembly of bioactive glass and $\mathrm{ZrTiO}_{4}$ particles to obtain more stable coating phases. This effect might be attributed to the flexibility of the drying liquid-vapor interface in the coatings through which the bioactive glass and $\mathrm{ZrTiO}_{4}$ particles can be protruded and arranged by selfassembly packing. One of the advantages of this technique is that the layers can be developed by using "bottom-up" assembly methods. ${ }^{24-28}$ This colloidal assembly is effective for having functional structures that take advantage of their nano- and micro-sized features. In this technique, the selfassembly is driven by solvent evaporation, which is a simple but effective platform for colloidal coating deposition. ${ }^{29}$

All samples were subjected to the adhesive tape test, and it is worth mentioning that all the samples passed this test and showed an adequate coating adhesion. The typical low and high magnifications of SEM micrographs of the triple-coated samples after the adhesive tape test are shown in Figure $3 \mathrm{~A}$ and $\mathrm{B}$, respectively. As can be seen, the edge of the cuts was completely smooth and none of the squares of the lattice were detached, indicating the desirable adhesion of the coatings.

Figure 4 shows the three-dimensional AFM micrographs of the uncoated, mono-, double-, and triple-layered coated samples, suggesting uniform and dense films. The AFM micrographs also show that the coatings consist of globular nanoparticles with a size of $15 \mathrm{~nm}$ to $130 \mathrm{~nm}$ and an average diameter of $50 \mathrm{~nm}$. This type of crack-free and uniform
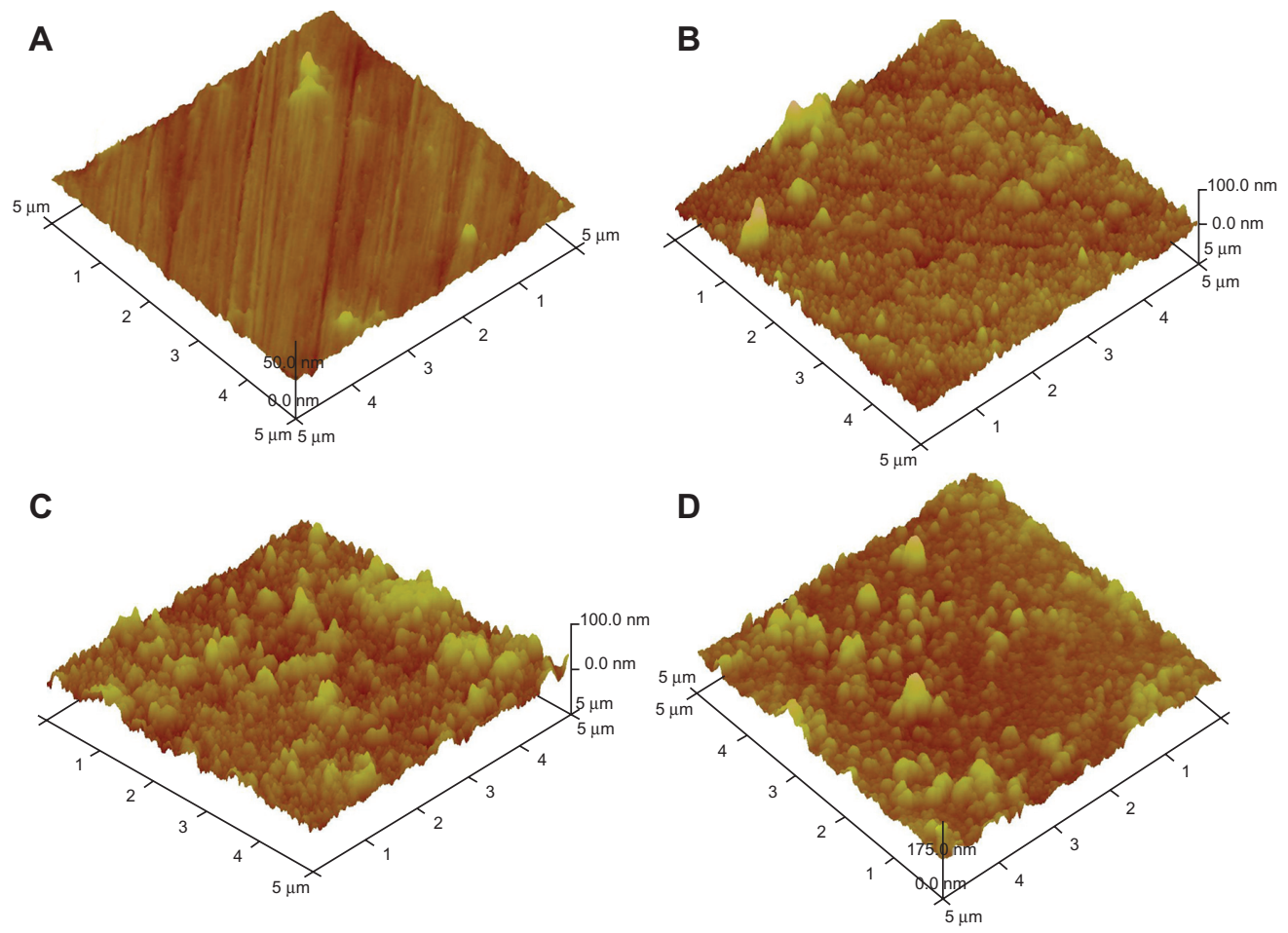

Figure 4 Three-dimensional atomic force microscope images of the surface of the uncoated samples (A) and the mono- (B), double- (C), and triple-layered (D) coated samples. 
coating can be advantageous in different applications, including tissue engineering implants. For instance, these coatings are expected not only to protect the surface of metallic implants against corrosion, but also advantageously affect hydrophilicity, biocompatibility, or bioactivity.

Surface roughness plays a crucial role in determining the functional performance of many devices. AFM allows determining the roughness value by considering the distribution curve of relative height among points in the scanning area, and by calculating the average value with respect to a central plane..$^{30-32}$ The average roughness value of the mono-, double-, and triplelayer coated samples over areas of $5 \times 5 \mu^{2}$ is presented in Figure 5, extracted from the AFM analyses using the DI NanoScope 7.20 software (VEECO, Mannheim, Germany). It can be seen that, by increasing the number of the layers, the roughness increased slightly, despite the fact that some of the pores and defects in the previous layer were covered by the subsequent layer, as explained above in the thickness assessment. During the sintering process of nanoparticles, some particles might start growing on the surface due to mass transfer caused by transformation from the glassy state to crystalline state. ${ }^{33}$ According to the Stranski-Krastanov growth model, after the formation of a continuous layer on the substrate, three-dimensional crystal islands tend to grow on that layer, ${ }^{34,35}$ thereby providing rough films with a large number of valleys and mountains.

The lattice mismatch between each layer can lead to the growth of a strained film. In a strained film, the formation of islands is energetically favorable, as it reduces the strain energy in the crystal. Similar observations are made in InAs/GaAs systems. ${ }^{36}$ Afterwards, the next deposited layer before sintering would smooth the surface and create a very small roughness value. But due to sintering of the newly deposited layer, if

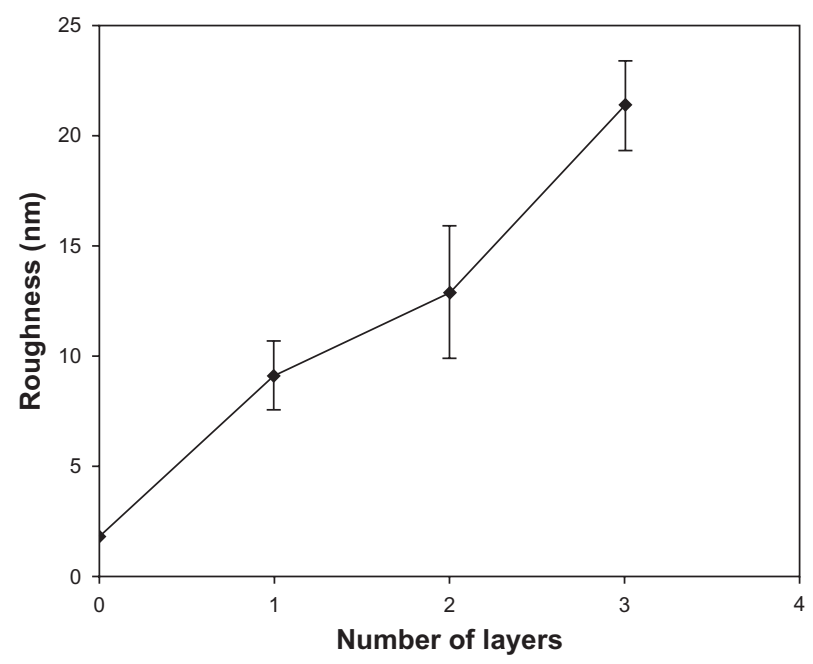

Figure 5 Roughness values of the deposited films. new islands are formed through valleys of the previous film or shrinkage in the valleys is less than that in the mountains, the roughness would decrease. Here, the increment of the film roughness by increasing the number of the layers suggested that this circumstance does not exist or does not dominate. On the other hand, it has been reported that residual stresses in the previous layers constrict the final layer and avoid the uniform coverage of the surface, increasing roughness. ${ }^{37}$

The biomineralization capability of the samples was investigated by monitoring the formation of apatite on the surface of the coated samples by FTIR analysis. Figure 6A-C shows the FTIR spectra of the triple-layered coated sample after 1, 3, and 7 days of immersion in the SBF solution, respectively. As can be seen, the bands observed at 382, 399, 950, and $965 \mathrm{~cm}^{-1}$ were ascribed to $\mathrm{P}-\mathrm{O}$ bending. The bands at 711 and $782 \mathrm{~cm}^{-1}$ indicated the presence of $\mathrm{CO}_{3}{ }^{2-}$ groups on the surface of the sample. These carbonate groups were promoted by increasing the immersion time indicating the formation of hydroxycarbonate apatite which is associated with the development of a layer consisting of carbonate-containing hydroxyapatite similar to that of bone on the surface of the coating. In addition, two characteristic bonds at $500 \mathrm{~cm}^{-1}$ were observed due to the stretching mode

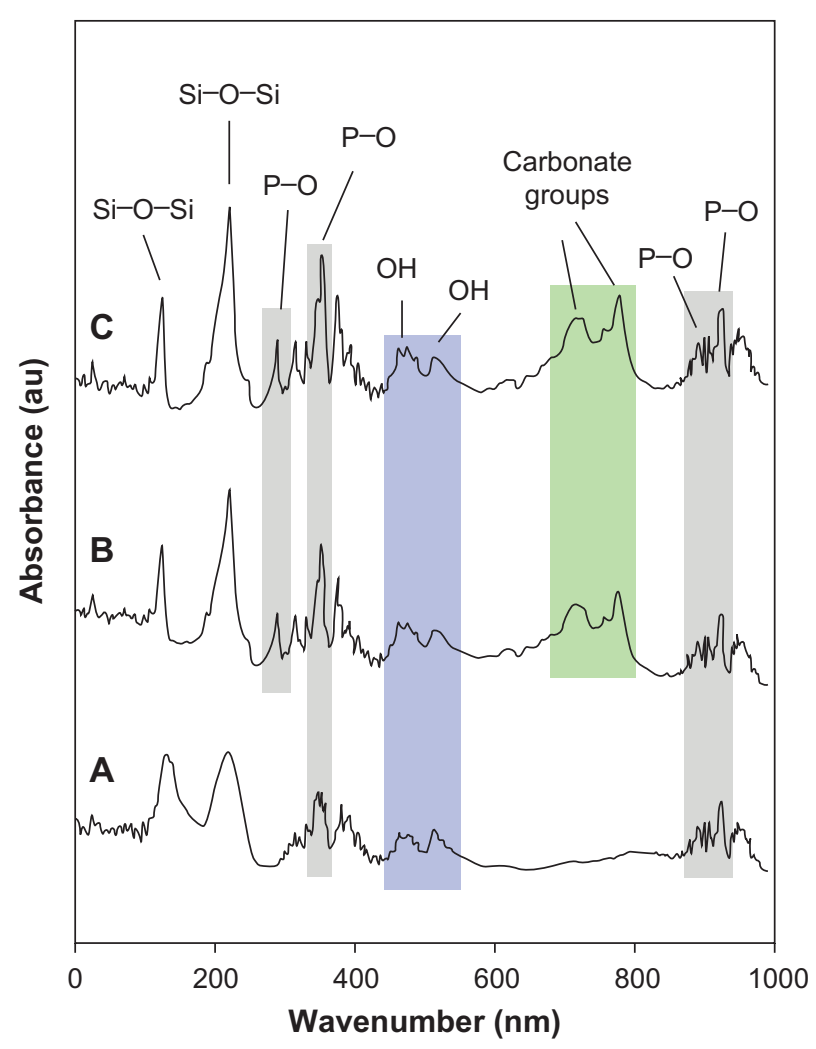

Figure 6 Fourier transform infrared (FTIR) spectra of the triple-layered coated sample after I (A), 3 (B), and 7 (C) days of immersion in the simulated body fluid solution. 
of hydrogen-bonded $\mathrm{OH}^{-}$ions and liberational mode of hydrogen-bonded $\mathrm{OH}^{-}$ions. The FTIR analysis showed all typical absorption characteristics of apatite.

In summary, the crack-free and high-coverage bioactive glass $/ \mathrm{ZrTiO}_{4}$ thin films were successfully deposited on the stainless steel implants. The study of the biological response of this new coating could be an interesting subject, since these properties are strongly affected by roughness and bioactivity. Certainly, the biological behavior of the prepared implants needs to be studied further for a precise conclusion.

\section{Conclusion}

In this research, multilayer bioactive glass $/ \mathrm{ZrTiO}_{4}$ thin films, applicable in bone tissue engineering, were successfully prepared by a sol-gel method using CMC as the dispersant. The microstructural observations indicated the formation of well-covering, crack-free, and homogeneous $\mathrm{ZrTiO}_{4}$ thin films, suggesting the merit of the processing. A nonlinear increase in the thickness and roughness of the films was found by increasing the number of the layers.

\section{Acknowledgment}

This work was partially supported by Air Force Office of Scientific Research under Grant no FA9550-10-1-0010 and the National Science Foundation under Grant no 0933763.

\section{Disclosure}

The authors report no conflicts of interest in this work.

\section{References}

1. Kamalian R, Yazdanpanah A, Moztarzadeh F, et al. Synthesis and characterization of bioactive glass/forsterite nanocomposites for bone implants. Ceramics-Silikáty. 2012;56:331-340.

2. Pandolfi L, Kaciulis S, Padeletti G, Cusmà A, Viticoli M. Deposition and characterization of $\mathrm{ZrTiO}_{4}$ thin films. Surf Interface Anal. 2004;36: $1159-1162$.

3. Hu MZC, Payzant EA, Booth KR, Rawn CJ, Hunt RD, Allard LF. Ultrafine microsphere particles of zirconium titanate produced by homogeneous dielectric-tuning coprecipitation. Journal of Materials Science. 2003;38:3831-3844.

4. Cosentino IC, Muccillo ENS, Muccillo R. Development of zirconiatitania porous ceramics for humidity sensors. Sens Actuators B. 2003;96: 677-683.

5. Lakshmi JL, Ihasz NJ, Miller JM. Synthesis, characterization and ethanol partial oxidation studies of $\mathrm{V}_{2} \mathrm{O}_{5}$ catalysts supported on $\mathrm{TiO}_{2}-$ $\mathrm{SiO}_{2}$ and $\mathrm{TiO}_{2}-\mathrm{ZrO}_{2}$ sol-gel mixed oxides. $J$ Mol Catal A Chem. 2001; 165:199-209.

6. Bokhimi X, Morales A, Novaro O, et al. Tetragonal nanophase stabilization in nondoped sol-gel zirconia prepared with different hydrolysis catalysts. J Solid State Chem. 1998;135:28-35.

7. Carp O, Huisman CL, Reller A. Photoinduced reactivity of titanium dioxide. Progress in Solid State Chemistry. 2004;32:33-177.

8. Reddy BM, Khan A. Recent advances on $\mathrm{TiO} 2-\mathrm{ZrO} 2$ mixed oxides as catalysts and catalyst supports. Catalysis Reviews: Science and Engineering. 2005;47:257-296.
9. Bavya Devi K, Singh K, Rajendran N. Sol-gel synthesis and characterisation of nanoporous zirconium titanate coated on $316 \mathrm{~L}$ SS for biomedical applications. Journal of Sol-Gel Science and Technology. 2011;59:513-520.

10. Hench LL, Buscemi PJ, inventors; Board of Regents State of Florida, assignee. Bioglass coated metal substrate. United States patent US 4234972. November 25, 1980.

11. Floroian L, Sima F, Florescu M, et al. Double layered nanostructured composite coatings with bioactive silicate glass and polymethylmetacrylate for biomimetic implant applications. J Electroanal Chem. 2010;648:111-118.

12. Yazdanpanah A, Kamalian R, Moztarzadeh F, Ravarian R, Mozafari M, Tayebi L. Enhancement of fracture toughness in bioactive glass-based nanocomposites with nanocrystalline forsterite for bone tissue engineering applications. Ceramics International. 2012; 38:5007-5014.

13. Scriven LE. Physics and applications of dip coating and spin coating. MRS Proceedings. 1988;121:717-729.

14. Daniels BK, Szmanda CR, Templeton MK, Trefonas PK III. Surface Tension Effects in Microlithography-Striations. Proc SPIE. 1986;631:192.

15. Rehg TJ, Higgins BG. Spin coating of colloidal suspensions. AIChE Journal. 1992;38:489.

16. Taherkhani S, Moztarzadeh F, Mozafari M, Lotfibakhshaiesh N. Sol-gel synthesis and characterization of unexpected rod-like crystal fibers based on $\mathrm{SiO}_{2}-(1-\mathrm{x}) \mathrm{CaO}-\mathrm{xSrO}-\mathrm{P}_{2} \mathrm{O}_{5}$ dried-gel. J Non Cryst Solids. 2012;358:342-348.

17. Salahinejad E, Hadianfard MJ, Macdonald DD, Karimi I, Vashaee D, Tayebi L. Aqueous sol-gel synthesis of zirconium titanate $\left(\mathrm{ZrTiO}_{4}\right)$ nanoparticles using chloride precursors. Ceramics International. 2012;38:6145-6149.

18. Salahinejad E, Hadianfard MJ, Macdonald DD, Mozafari M, Vashaee D, Tayebi L. Multilayer zirconium titanate thin films prepared by a sol-gel deposition method. Ceramics International. 2013;39:1271-1276.

19. Salahinejad E, Hadianfard MJ, Macdonald DD, Mozafari M, Vashaee D, Tayebi L. Zirconium titanate thin film prepared by an aqueous particulate sol-gel spin coating process using carboxymethyl cellulose as dispersant. Mater Lett. 2012;88:5-8.

20. Morrison DI, Ross S. Colloidal Dispersions. New York: Wiley Interscience; 2002.

21. Hiemenz CP, Rajagopalan R. Principles of Colloid and Surface Chemistry. New York: Marcel Dekker; 1997.

22. Sato T, Ruch R. Stabilization of Colloidal Dispersions by Polymer Adsorption. New York: Marcel Dekker; 1980.

23. Song S, Lopez-Valdivieso A, Martinez-Martinez C, Torres-Armenta R. Improving fluorite flotation from ores by dispersion processing. Miner Eng. 2006;19:912-917.

24. Caruso F, editor. Colloids and Colloid Assemblies: Synthesis, Modification, Organization and Utilization of Colloid Particles, 1st ed. Weinheim: Wiley-VCH Verlag GmbH and Co KGaA; 2004.

25. Shipway AN, Katz E, Willner I. Nanoparticle arrays on surface for electronic, optical, and sensor application. Chem Phys Chem. 2000;1:18-52.

26. Vlasov YA, Bo XZ, Sturm JC, Norris DJ. On-chip natural assembly of silicon photonic bandgap crystals. Nature. 2001;414:289-293.

27. Joannopoulos JD. Photonics: self-assembly lights up. Nature. 2001;414:257-258.

28. Velev OD. Handbook of Surfaces and Interfaces of Materials. London: Academic Press; 2001:1-43.

29. Naghib SM, Ansari M, Pedram A, Moztarzadeh F, Feizpour A, Mozafari M. Bioactivation of 304 stainless steel surface through 45S5 bioglass coating for biomedical applications. International Journal of Electrochemical Science. 2012;7:2890-2903.

30. Allahkarami M, Hanan JC. Mapping the tetragonal to monoclinic phase transformation in zirconia core dental crowns. Dent Mater. 2011;27:1279-1284.

31. Zhang Y, Allahkarami M, Hanan JC. Measuring residual stress in ceramic zirconia-porcelain dental crowns by nanoindentation. $J$ Mech Behav Biomed Mater. 2012;6:120-127. 
32. Farajia LS, Singh RP, Allahkarami M. Pulsed laser deposition of bismuth telluride thin film and annealing effects. The European Physical Journal-Applied Physics. 2009;46:20501-20505.

33. Satapathy S, Verma P, Gupta PK, Mukherjee C, Sathe VG, Varma KBR. Structural, dielectric and ferroelectric properties of multilayer lithium tantalate thin films prepared by sol-gel technique. Thin Solid Films. 2011;519:1803-1808.

34. Tassev VL, Bliss DF. Stranski, Krastanov, and Kaischew, and their influence on the founding of crystal growth theory. J Crystal Growth. 2008;310: 4209-4216.
35. Matthews JW, editor. Epitaxial Growth. New York: Academic Press; 1975:566

36. Petroff PM, Denbaars SP. MBE and MOCVD growth and properties of self-assembling quantum dot arrays in III-V semiconductor structures. Superlattices and Microstructures. 1994;15:15.

37. Vaghari H, Sadeghian Z, Shahmiri M. Investigation on synthesis, characterisation and electrochemical properties of $\mathrm{TiO}_{2}-\mathrm{Al}_{2} \mathrm{O}_{3}$ nanocomposite thin film coated on $316 \mathrm{~L}$ stainless steel. Surf Coat Technol. 2011;205:5414-5421.

\section{Publish your work in this journal}

The International Journal of Nanomedicine is an international, peerreviewed journal focusing on the application of nanotechnology in diagnostics, therapeutics, and drug delivery systems throughout the biomedical field. This journal is indexed on PubMed Central, MedLine, CAS, SciSearch ${ }^{\circledR}$, Current Contents ${ }^{\circledR} /$ Clinical Medicine,
Journal Citation Reports/Science Edition, EMBase, Scopus and the Elsevier Bibliographic databases. The manuscript management system is completely online and includes a very quick and fair peer-review system, which is all easy to use. Visit http://www.dovepress.com/ testimonials.php to read real quotes from published authors. 